\title{
TU/e EnNHOUN

\section{Stacked low-growth-rate InAs quantum dots studied at the atomic level by cross-sectional scanning tunneling microscopy}

\section{Citation for published version (APA):}

Bruls, D. M., Koenraad, P. M., Salemink, H. W. M., Wolter, J. H., Hopkinson, M., \& Skolnick, M. S. (2003). Stacked low-growth-rate InAs quantum dots studied at the atomic level by cross-sectional scanning tunneling microscopy. Applied Physics Letters, 82(21), 3758-3760. https://doi.org/10.1063/1.1578709

DOI:

10.1063/1.1578709

Document status and date:

Published: 01/01/2003

\section{Document Version:}

Publisher's PDF, also known as Version of Record (includes final page, issue and volume numbers)

\section{Please check the document version of this publication:}

- A submitted manuscript is the version of the article upon submission and before peer-review. There can be important differences between the submitted version and the official published version of record. People interested in the research are advised to contact the author for the final version of the publication, or visit the $\mathrm{DOI}$ to the publisher's website.

- The final author version and the galley proof are versions of the publication after peer review.

- The final published version features the final layout of the paper including the volume, issue and page numbers.

Link to publication

\section{General rights}

Copyright and moral rights for the publications made accessible in the public portal are retained by the authors and/or other copyright owners and it is a condition of accessing publications that users recognise and abide by the legal requirements associated with these rights.

- Users may download and print one copy of any publication from the public portal for the purpose of private study or research.

- You may not further distribute the material or use it for any profit-making activity or commercial gain

- You may freely distribute the URL identifying the publication in the public portal.

If the publication is distributed under the terms of Article 25fa of the Dutch Copyright Act, indicated by the "Taverne" license above, please follow below link for the End User Agreement:

www.tue.nl/taverne

Take down policy

If you believe that this document breaches copyright please contact us at:

openaccess@tue.nl

providing details and we will investigate your claim. 


\title{
Stacked low-growth-rate InAs quantum dots studied at the atomic level by cross-sectional scanning tunneling microscopy
}

\author{
D. M. Bruls, ${ }^{\text {a) }}$ P. M. Koenraad, H. W. M. Salemink, and J. H. Wolter \\ COBRA Inter-University Research Institute, Department of Applied Physics, Eindhoven University \\ of Technology, P.O. Box 513, 5600 MB Eindhoven The Netherlands \\ M. Hopkinson \\ Department of Electronic and Electrical Engineering, University of Sheffield, Mappin Street, Sheffield S1 3JD, \\ United Kingdom
}

M. S. Skolnick

Department of Physics and Astronomy, University of Sheffield, Sheffield S3 7RH, United Kingdom

(Received 13 February 2003; accepted 28 March 2003)

\begin{abstract}
Structures containing stacked self-assembled InAs quantum dots within a GaAs matrix are studied by cross-sectional scanning tunneling microscopy. The dots consist of an InGaAs alloy with an increasing indium concentration in the growth direction. From comparison of the lattice constant profiles of stacked and unstacked dots, it is evident that the strain in the GaAs matrix around the dots is strongly affected by the stacking process. The results show an increasing deformation of the dots in the stack and a reduced growth rate of the GaAs spacer layers, resulting in the formation of terraces on the growth surface on which new dots form. If the total structure, containing the dot layers and the spacer layers, exceeds $30 \mathrm{~nm}$, the local GaAs growth rate remains constant from this point on. The InAs dot growth rate remains constant throughout the entire stack. (C) 2003 American Institute of Physics. [DOI: 10.1063/1.1578709]
\end{abstract}

The opto-electronic properties of self-assembled dots (SADs) are strongly affected by their shape and composition. $^{1-6}$ The interpretation of most experiments performed on SADs is, however, strongly hampered by a lack of proper knowledge of the shape and composition parameters. Although in some transmission electron microscopy (TEM) studies $^{7,8}$ these parameters were successfully determined, the resolution obtained in TEM on buried dots is not necessarily atomic $^{1,2,6,9}$ as the contrast between InAs and GaAs is very weak and the strain distribution is mostly imaged.

We have studied stacked InAs quantum dots (QDs) in a GaAs matrix by cross-sectional scanning tunneling microscopy (X-STM). By using X-STM, the internal structure of buried SADs can be resolved both qualitatively and quantitatively. If the spacing between QD layers is sufficient small $(<25 \mathrm{~nm})$, stacks of dots are formed (see Fig. 1), as it is energetically favorable to form a dot in the strain field of a previous dot to reduce the surface free energy. ${ }^{10-15}$ It is generally assumed that this stacking process may be advantageous for high uniformity in size and shape of these dots. This is needed for improved device functionality, like low laser threshold currents, improved stability upon temperature changes, and narrow luminescence line widths. ${ }^{10,12,14,15}$ Furthermore, the density of the QDs has to be as high as possible in order to obtain an increased laser output power. In Fig. 1, it can be seen that two different stacks have the same morphology, which shows the general behavior of the stacking process.

All X-STM measurements were performed under UHV ( $p<6 \times 10^{-11}$ mbar) conditions, using an Omicron STM1,

${ }^{a) E l e c t r o n i c ~ m a i l: ~ d . m . b r u l s @ t u e . n l ~}$
TS-2 scanner in the constant current mode, on in situ cleaved (110) surfaces. The preparation of the STM tips was as described in Ref. 16. All structures were grown by molecular beam epitaxy (MBE) at $512^{\circ} \mathrm{C}$ and contained five layers of low growth rate [0.01 monolayers (ML)/s, $2.4 \mathrm{ML}$ InAs per layer deposited] Stranski-Krastanov grown InAs QDs within a GaAs matrix. The dot layers were coupled, as the GaAs spacer layer was only $10 \mathrm{~nm}$.

By investigating the STM current image (Fig. 2), the real shape and internal structure of the stack become more clear, as these current images show the "spatial derivative" of the height image, thus enhancing the distinction between the dot material and the surrounding GaAs matrix.

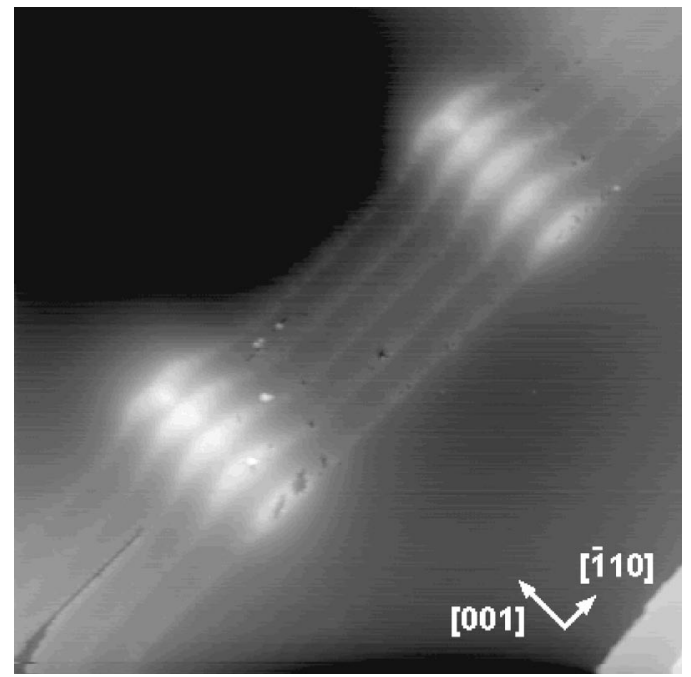

FIG. 1. X-STM constant current topography image of two stacks of InAs QDs. Image size $150 \times 150 \mathrm{~nm}^{2}, V_{\text {sample }}=-2.57 \mathrm{~V}, I_{\text {tunnel }}=147 \mathrm{pA}$. 


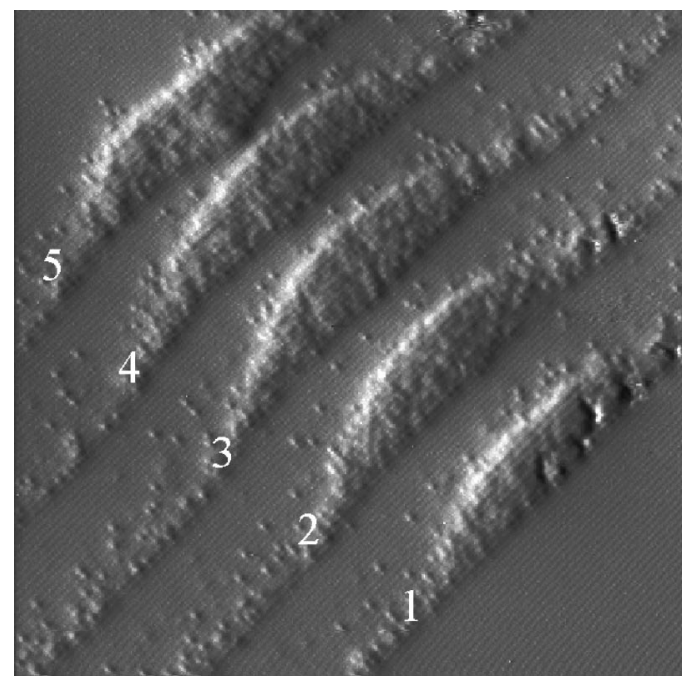

FIG. 2. X-STM current image of a stack of MBE-grown $\left(512^{\circ} \mathrm{C}\right)$ InAs SADs in GaAs (image size $55 \times 55 \mathrm{~nm}^{2}$ ). The structure contains five SAD layers formed after deposition of 2.4 ML of InAs for each SAD layer.

We observed that the internal structure is clearly nonhomogeneous (see Fig. 2), that is, small, short-ranged fluctuations inside the dots are visible. This shows that the dots consist of an InGaAs alloy. This alloy formation is well known from STM measurements on uncapped InAs QD structures. ${ }^{4}$ The presence of an indium concentration gradient in uncoupled QD layers, grown under similar conditions, was also concluded from photocurrent measurements, finite element calculations, TEM measurements, ${ }^{1,3,7}$ and our previous X-STM work ${ }^{17,18}$ where we obtained detailed information about the shape, size, and composition profiles of the QDs.

The lattice constant inside the stacked dots increases from bottom to top (see Fig. 3). This indicates that the indium concentration inside the dots increases from bottom to top, as the local lattice constant is linked to the local indium concentration. ${ }^{17,18}$ The reduction of the lattice constant in the GaAs surrounding the dot is stronger for stacked dots as for isolated dots ${ }^{17}$ (Fig. 3). The larger strain in the GaAs matrix may reduce the GaAs growth rate [two-dimensional (2D)] on top of the dots during stack formation.

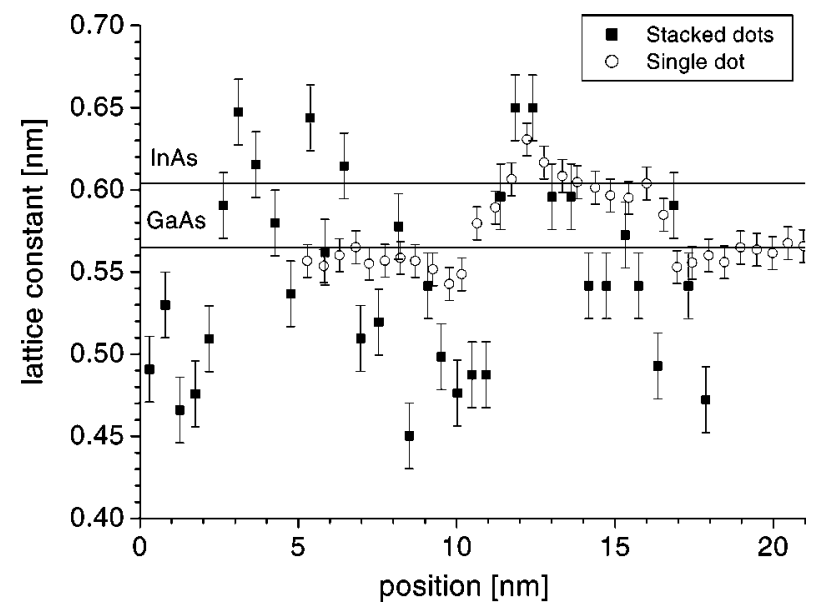

FIG. 3. Lattice constant profiles in the growth direction of the last two InAs QDs inside the stack and a single nonstacked dot. The growth direction runs

from right to left.
Downloaded 17 Jan 2008 to 131.155.108.71. Redistribution subject to AlP license or copyright; see http://apl.aip.org/apl/copyright.jsp

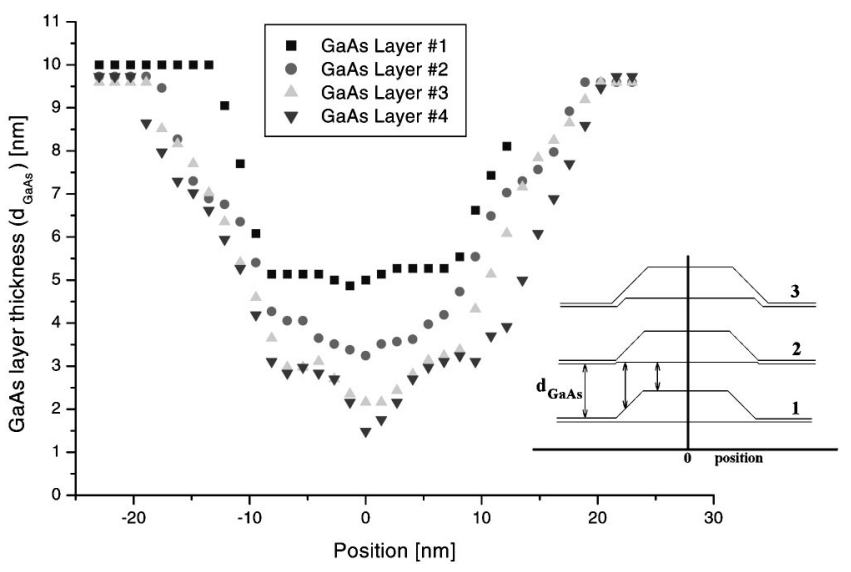

FIG. 4. GaAs spacer layer thickness throughout the stack as function of position with respect to the center of the stack

In Fig. 2, it can be seen that during growth the dots higher in the stack nucleate at the apex of previously buried dots, thus forming the stack. ${ }^{10,11,13}$ The dots in the second and following layers are formed at a position that is shifted slightly with respect to the wetting layer. This is due the in-complete planarization effect of the 2D GaAs growth, which tends to flatten out rough surfaces and suppresses terrace on terrace growth. It is also clear that the dots in the stack are not identical. A wing shaped deformation occurs, which gets more pronounced higher in the stack. This is a disadvantage for dot uniformity and most probably for the suitability for device fabrication. Finally it is interesting to note that the indium segregation above the dots is less than in the wetting layer.

In order to understand these effects and especially the deformation of the dot shape throughout the stack, we have investigated the local thickness of the GaAs spacer layers (Fig. 4) and the InAs dot layers (Fig. 5) as function of lateral position (with respect to the center of the stack). These layer thickness profiles give an indication of growth-rate changes during the stacking process.

Figure 4 shows that the GaAs spacer layer in between the dots decreases in each subsequent layer up to layer 3 . We observe that the GaAs growth rate in the area above the dots is almost constant for the first and second GaAs layers. After

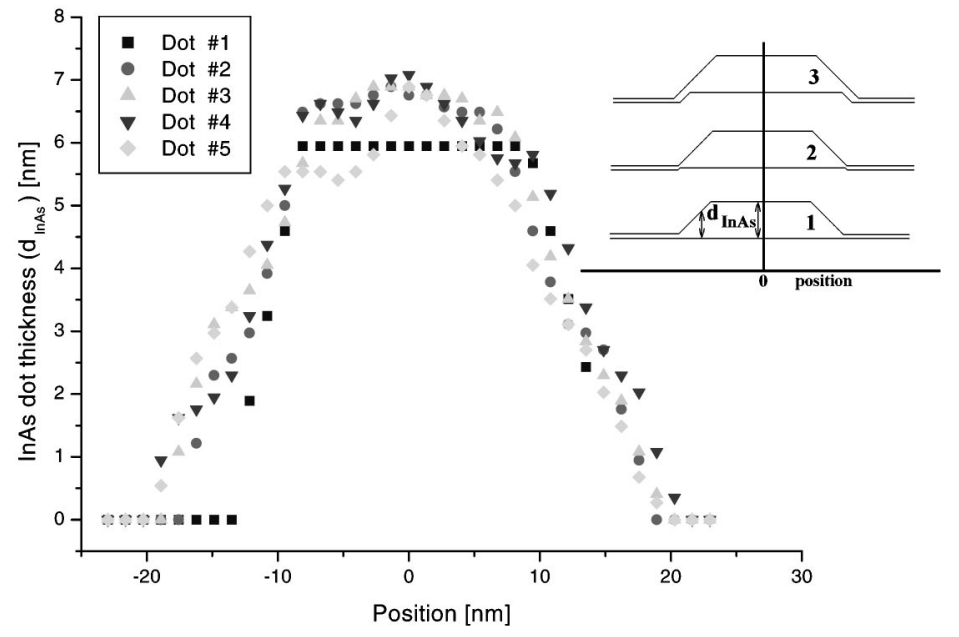

FIG. 5. InAs dot thickness throughout the stack as function of position, with

respect to the center of the stack.
AlP license or copyright; see http://apl.aip.org/apl/copyright.jsp 
layer 3, the spacer layer thickness profile remains the same, but the local growth rate above the dots is no longer constant, since it decreases dramatically near the center of the stack. The observation that the GaAs spacer layer thickness profile hardly changes after the third layer, must be due to the fact that the strain field of dot 1 influences the material up to spacer layer 3, so up to $30 \mathrm{~nm}$ from the dot layer. This is close to the maximum spacer layer thickness $(25-30 \mathrm{~nm})$ between subsequent dot layers at which stacking will still occur. $^{10}$

The specific growth-speed profile of the GaAs spacers (Fig. 4), with the extreme minimum at the center of layers 4 and 5 cannot be explained by the well-known planarization effect. Although we cannot fully explain the near-complete absence of GaAs growth at the center of the spacer layer between dot layers 4 and 5, we think that the surface strain and thermodynamic effects play an essential role. We image that it is thermodynamically unfavorable for GaAs to grow on top of an almost fully relaxed InAs dot surface, compared to the area of the wetting layer, where the lattice constant is closer to that of GaAs. The results indicate that there is a critical number of stacked dots, above which the forementioned effects are stronger than the normal planarization effect.

We propose that the reduced indium segregation above the dots can be explained in the following way. An indium atom that would diffuse from the dot to the GaAs spacer layer, would give up a position that is energetically rather favorable, for a position that is highly unfavorable, that is, an indium atom inside heavily tensile strained GaAs. Therefore, the indium will remain in the top of the dot, where the lattice constant is more comparable to that of InAs. ${ }^{2,5}$

The dot thickness profile (measured from the local position of the GaAs/InAs wetting layer interface up to the top of the dot) is equal in each dot layer, as is shown in Fig. 5. Thus, the volume of each subsequent dot is the same. This is to be expected because the amount of deposited InAs is equal for all dot layers, assuming the wetting layer and alloy formation is the same in all layers. In addition, no dots outside a stack are observed, meaning that for all QD layers the number of nucleation sites remains constant.

We therefore conclude that the deformation of the dots throughout the stack is caused mainly by the changes in local growth rate of the GaAs spacer layer and not by the local InAs growth rate. The GaAs growth rate is more sensitive to strain fields originating from relatively deep inside the material than is the InAs dot growth rate, due to the fact that the dots are formed in the Stranski-Krastanov growth mode. This growth mode is based on the relief of built in strain of the wetting layer by a transition from 2D to threedimensional (3D) growth. Local strain fluctuations determine the position where the dots are formed. The 3D formation process of the dot, however, seems to be influenced mainly by the total amount of material deposited, so by the total amount of strain in the entire wetting layer. The GaAs spacer layers, however, are epitaxially (2D) grown on top of the dots. The "thermodynamically driven" local growth rate is in this case very sensitive to local (especially lateral) strain variations.

In conclusion, X-STM has been used to analyze the structural properties of stacked InAs quantum dots. The dots consist of an InGaAs alloy, with an increasing indium concentration in the growth direction. The lattice constant profiles show that the stacking causes an extra increase of the compressive strain the GaAs matrix around the dots compared to isolated dots, whereas the InGaAs dot material seems to be less affected by the stack formation. The deformation of the dots throughout the stack can be explained by the decreasing GaAs growth rate of the spacer layer, which is caused by the different mechanisms involved in the 2D growth of the GaAs spacer layers, which is very sensitive to local strain fluctuations, and the 3D growth of the InAs quantum dots, which depends mainly of the total amount of strain in the total wetting layer before dot formation takes place. Although dot deformation inside the stack occurs, the growth rate and the volume of the InAs dots remain constant throughout the stack.

${ }^{1}$ P. W. Fry, I. E. Itskevich, D. J. Mowbray, M. S. Skolnick, J. J. Finley, J. A. Barker, E. P. O'Reilly, L. R. Wilson, I. A. Larkin, P. A. Maksym, M. Hopkinson, M. Al-Khafaji, J. P. R. David, A. G. Cullis, G. Hill, and J. C. Clark, Phys. Rev. Lett. 84, 733 (2000).

${ }^{2}$ A. Rosenauer, W. Oberst, D. Litvinov, D. Gerthsen, A. Förster, and R. Schmidt, Phys. Rev. B 61, 8276 (2000).

${ }^{3}$ J. A. Barker and E. P. O'Reilly, Phys. Rev. B 61, 13840 (2000).

${ }^{4}$ P. B. Joyce, T. J. Krzyzewski, G. R. Bell, B. A. Joyce, and T. S. Jones, Phys. Rev. B 58, 15981 (1998).

${ }^{5}$ I. Kegel, T. H. Metzger, A. Lorke, J. Peisl, J. Stangl, G. Bauer, J. M. Garcia, and P. M. Petroff, Phys. Rev. Lett. 85, 1694 (2000).

${ }^{6}$ D. Zhi, H. Davock, R. Murray, C. Roberts, T. S. Jones, D. W. Pashley, P. J. Goodhew, and B. A. Joyce, J. Appl. Phys. 89, 2079 (2001).

${ }^{7}$ T. Walther, A. G. Cullis, D. J. Norris, and M. Hopkinson, Phys. Rev. Lett. 86, 2381 (2001).

${ }^{8}$ A. G. Cullis, D. J. Dorris, T. Walther, M. A. Migliorato, and M. Hopkinson, Phys. Rev. B 66, 081305(R) (2002).

${ }^{9}$ J. P. McCaffrey, M. D. Robertson, S. Fafard, Z. R. Wasilewski, E. M. Griswold, and L. D. Madsen, J. Appl. Phys. 88, 2272 (2000).

${ }^{10}$ Q. Xie, A. A. Madhukar, P. Chen, and N. P. Kobayashi, Phys. Rev. Lett. 75, 2542 (1995).

${ }^{11}$ H. Eisele, O. Flebbe, T. Kalka, C. Preinesberger, F. Heinrichsdorff, A. Krost, D. Bimberg, and M. Dähne-Prietsch, Appl. Phys. Lett. 75, 106 (1999).

${ }^{12}$ N. N. Ledentsov, V. A. Schukin, M. Grundman, N. Kirstaedter, J. Böhrer, O. Schmidt, D. Bimberg, V. M. Utsinov, A. Yu. Egorov, A. E. Zhukov, P. S. Kop'ev, S. V. Zaitsev, N. Yu. Gordeev, Zh. I. Alferov, A. I. Borovkov, A. O. Kosogov, S. S. Ruvimov, P. Werner, U. Gösele, and J. Heydenreich, Phys. Rev. B 54, 8743 (1996).

${ }^{13}$ B. Legrand, J. P. Nys, B. Grandidier, D. Stivenard, A. Lamaître, J. M. Gérard, and V. Thierry-Mieg, Appl. Phys. Lett. 74, 2608 (1999).

${ }^{14}$ J. Tersof, C. Teichert, and M. G. Lagally, Phys. Rev. Lett. 76, 1675 (1996).

${ }^{15}$ O. G. Schmidt, N. Kirstaedter, N. N. Ledentsov, M.-H. Mao, D. Bimberg, V. M. Ustinov, A. Y. Egorov, A. E. Zhukov, M. V. Maximov, P. S. Kop'ev, and Z. I. Alferov, Electron. Lett. 32, 1302 (1996).

${ }^{16}$ G. J. de Raad, P. M. Koenraad, and J. H. Wolter, J. Vac. Sci. Technol. B 17, 1946 (1999).

${ }^{17}$ D. M. Bruls, J. W. A. M. Vugs, P. M. Koenraad, M. Hopkinson, M. S. Skolnick, Fei Long, and S. P. A. Gill, Appl. Phys. Lett. 81, 1708 (2002).

${ }^{18}$ D. M. Bruls, J. W. A. M. Vugs, P. M. Koenraad, M. S. Skolnick et al., Appl. Phys. A: Mater. Sci. Process. 72 [Suppl.], S205 (2001). 